\title{
INFLUÊNCIA DA SUCÇÃO MÁTRICA NAS CONDIÇÕES DE FLUXO E ESTABILIDADE DE TALUDES DE UMA BARRAGEM DE TERRA
}

\author{
Rosiel Ferreira Leme, Silvrano Adonias Dantas Neto, \\ Francisco CHAGAS DA Silva FilHo \\ Universidade Federal do Ceará (UFC) \\ <rosielferreira@gmail.com>, <silvrano@ufc.br> \\ $<$ fchagasfilho@gmail.com>
}

DOI: $10.21439 /$ conexoes.v10i2.750

\begin{abstract}
Resumo. Este trabalho tem como principal meta avaliar a influência da não saturação dos solos na estabilidade dos taludes durante o período de operação em barragens de terra. Para isto, foi realizado um estudo de estabilidade de taludes para a Barragem de Pesqueiro-CE para avaliar a segurança da obra durante o período de operação. Os parâmetros geotécnicos utilizados nas análises foram obtidos a partir da realização de ensaios de laboratório em amostras extraídas no maciço da barragem e da jazida de empréstimo. As condições de poro-pressão na barragem foram obtidas por simulações numérica transientes, simulando a operação da barragem num período de 6 anos. Após a definição da variação das poro-pressões durante o regime operação, foram realizadas as análises de estabilidade de taludes considerando a não saturação do solo por meio da influência da sucção mátrica na resistência ao cisalhamento do solo, e por meio das metodologias tradicionais, as quais a sucção mátrica não é levada em conta na resistência ao cisalhamento dos materiais. Os resultados mostraram que, para o talude de jusante, a estabilidade não ocorre alterações significativas em ambas as metodologias adotadas, devido ao sistema de drenagem interno, diferente do talude de montante, que por conta das grandes alterações de poro-pressões, apresenta grandes variações de estabilidade no período estudado. Avaliando a influência da sucção na estabilidade, é verificado uma diferença média de $13,8 \%$ para o talude de jusante e uma diferença de pico de $29,6 \%$ para o talude de montante para ambas as metodologias.
\end{abstract}

Palavras-chaves: Solos não saturados. Barragem. Sucção mátrica.

\begin{abstract}
This work has as main objective to evaluate the influence of unsaturation of soils on slope stability during operation in earth dams. For this, a study of slope stability for Pesqueiro Dam was performed to evaluate the safety of the work during the period of operation. Geotechnical parameters used in the analysis were obtained from the testing laboratory on samples taken at the dam and deposit of soil. The conditions of pore pressure in the dam were obtained by transient numerical simulations, simulating the operation of the dam over a period of 6 years. After defining the variation of water pressures during the operation period, the slope stability analysis considering the unsaturation of the soil through the influence of matric suction on the shear strength of the soil were carried out, and through traditional methodologies, which matric suction is not taken into account the shear strength of the material. The results showed that for the downstream slope, stability does not occur significant changes in both the methodologies adopted, due to the internal drainage system, different from the amount of slope, which because of huge changes in water pressures, varies widely stability during the study period. Evaluating the influence of suction in stability, observed difference is an average of 13,8\% for the downstream slope and a difference of $29,6 \%$ for the upstream slope for both methodologies.
\end{abstract}

Keywords: Unsaturated soils. Dam. Matric suction. 


\section{INTRODUÇÃO}

O comportamento dos solos não saturados sempre foi reconhecido no âmbito da Geotecnia desde seu estabelecimento como ramo do conhecimento dentro da engenharia. Entretanto, os princípios da mecânica dos solos clássica, usualmente praticada, não foram desenvolvidos levando em conta os efeitos provocados pela não saturação dos solos. Segundo Fredlund (1993), uma das razões disto deve-se provavelmente ao clima temperado dos países em que foram desenvolvidas as teorias da mecânica dos solos clássica, onde a presença de formações de solos saturados é predominante. Outra razão a qual pode ter influenciado no desenvolvimento da mecânica dos solos não saturados é que o comportamento do solo em seu estado saturado tende a ser mais crítico numa diversidade de situações.

Nos últimos anos, o ramo da Geotecnia tem-se caracterizado pelos esforços no sentido de compreender o comportamento dos solos não saturados, com o intuito de melhorar e aperfeiçoar projetos e construções, pois a não consideração do comportamento deste estado do solo tende a onerar os projetos, deixando de considerar uma grande parcela de resistência, diminuição das deformações nos maciços e aumento de permeabilidade, ocasionada pela atuação da sucção mátrica nos solos. De acordo com Oliveira (2004), diversas estruturas de engenharia têm sido construídas sobre solos não saturados, tais como, estradas, muros de contenção, barragens, fundações de edifícios, aterros compactados etc., e muitos problemas têm surgido em diversas partes do mundo sobre estes tipos de obras devido a esse fato.

Os problemas ocasionados em obras onde predominam os solos não saturados devem ser minimizados, sendo isto possível somente a partir do estudo mais aprofundado das particularidades inerentes a estes materiais e seu efeito sobre as suas propriedades, particularmente sobre a resistência ao cisalhamento, permeabilidade e deformabilidade. Isto faz com que a mecânica dos solos não saturados possa se tornar uma ferramenta importante a ser utilizada em projetos de engenharia geotécnica, levando a execução de obras mais racionais e econômicas.

Com a finalidade de se obter respostas sobre a influência das propriedades dos solos não saturados no comportamento de obras geotécnicas, este estudo consistiu em analisar o comportamento de uma barragem de terra durante o primeiro enchimento e operação, levando-se em consideração a variação da sucção mátrica e sua influência nas propriedades geotécnicas dos solos e nas condições de fluxo e estabilidade da barragem.

Para o desenvolvimento do estudo, escolheu-se a
Barragem Pesqueiro-CE como estudo de caso. Para tanto foi adotado um modelo numérico para definição das condições de fluxo transiente, e feita a avaliação da estabilidade dos taludes, sendo considerado em ambas as análises a influência da sucção mátrica no comportamento do material do barramento.

\section{MATERIAIS E MÉTODOS}

\subsection{Generalidades}

Neste item serão apresentados as metodologias empregadas e os resultados dos ensaios geotécnicos realizados em amostras de solo provenientes da Barragem Pesqueiro. Todos os ensaios foram executados no Laboratório de Mecânica dos Solos e Pavimentação da Universidade Federal do Ceará - UFC e no Laboratório de Mecânica dos Solos da Universidade de Fortaleza - UNIFOR.

O programa adotado para a realização dos ensaios consistiu em quatro etapas: obtenção de amostras, ensaios de caracterização, ensaios de resistência ao cisalhamento e ensaios para determinação das propriedades hidráulicas dos solos (permeabilidade e curva característica).

\subsection{Estudo de caso}

A Barragem Pesqueiro é atualmente uma importante reserva hídrica para a localidade do município de Capistrano, localizado no Estado do Ceará - Brasil. O açude dispõe de uma capacidade de aproximadamente 9,6 milhões de $\mathrm{m}^{3}$ de água, que garante segurança hídrica para a população local e mais quatro distritos do município. A seguir é apresentado um mapa de localização do empreendimento.

O Açude Pesqueiro é composto de um conjunto de obras constituído por uma barragem principal de terra homogênea de altura máxima de 24,20 m, um sangradouro do tipo soleira espessa, uma barragem auxiliar (Dique 1) também de terra homogênea e uma tomada d'água do tipo galeria, com controle a jusante. Sua construção foi concluída no início do ano de 2008. A Figura 2 apresenta a seção máxima obtida no Projeto As-Built.

\subsection{Ensaios de laboratório}

\subsubsection{Considerações iniciais}

Os ensaios de laboratório foram realizados para a obtenção dos parâmetros geotécnicos a serem utilizados nas simulações numéricas de fluxo e nas análises de estabilidade de taludes da barragem Pesqueiro. Desta forma, fez-se uma amostragem do solo utilizado para construir 


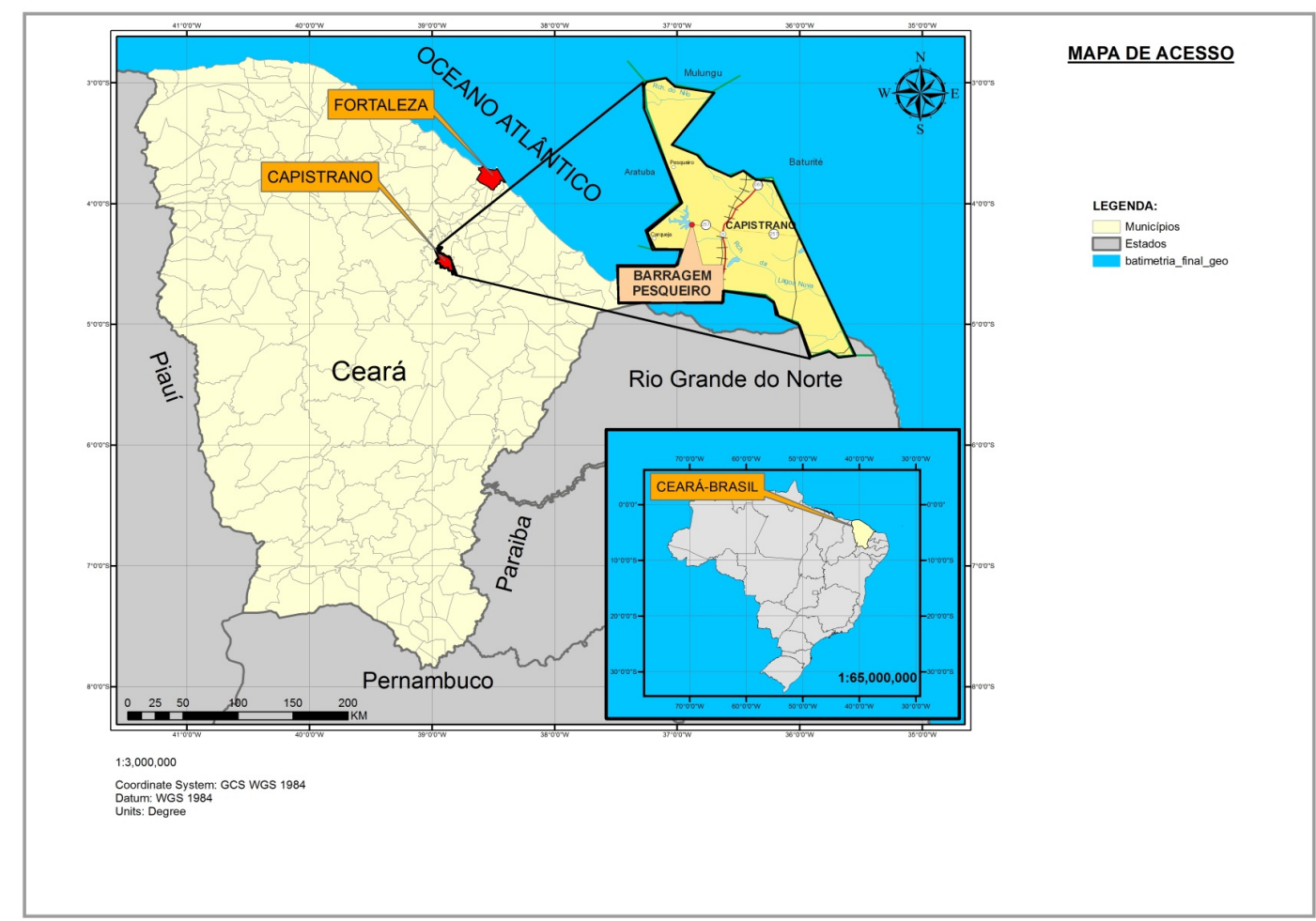

Figura 1: Localização da barragem Pesqueiro.

Fonte: (IPECE 2012), modificado pelos Autores (2015).

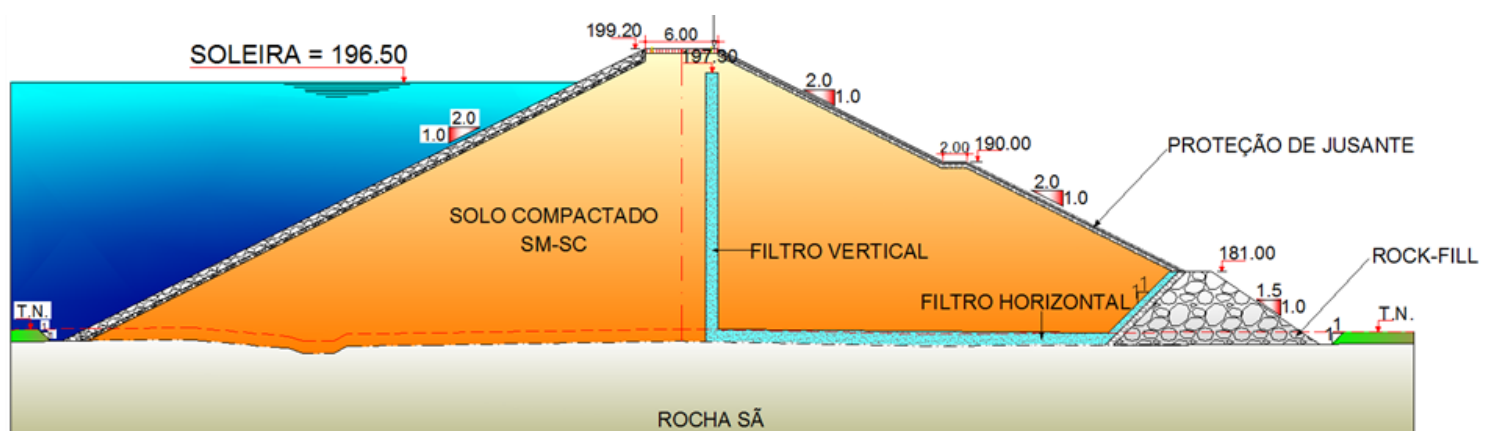

Figura 2: Seção máxima da barragem Pesqueiro. 
o maciço da barragem para a realização dos ensaios de laboratório.

\subsubsection{Amostragem}

Foram feitas dois tipos de amostragem: amostras deformadas e indeformadas. As amostras deformadas foram extraídas na Jazida de empréstimo da barragem que está localizada próximo à ombreira direita do maciço no lado montante. As amostras indeformadas (Figura 3) foram obtidas no maciço principal da Barragem Pesqueiro, nas proximidades da Estaca 16 onde está localizada a seção transversal máxima. A amostragem foi feita pela equipe técnica do Laboratório de Mecânica dos Solos e Pavimentação da UFC.

\subsubsection{Ensaios geotécnicos de caracterização, compactação e permeabilidade}

As amostras deformadas provenientes da jazida de empréstimo foram caracterizadas a partir da realização dos ensaios de granulometria, peso específico dos grãos, limite de liquidez e limite de plasticidade.

Também foram realizados ensaios de compactação para a determinação do peso especifico seco máximo e umidade ótima, utilizando-se a energia de Proctor Normal e seguindo-se as recomendações da NBR 7182/1986. Para a determinação da condutividade hidráulica do material realizou-se ensaios de permeabilidade sob carga variável, seguindo-se as orientações da norma NBR 14545/2000.

A Tabela 1 mostra os resultados dos ensaios geotécnicos realizados. Segundo o Sistema Unificado de Classificação dos Solos (SUCS), o material constituinte do material ensaiado foi classificado como SM (Areia Siltosa).

\subsubsection{Ensaio do Papel Filtro para Determinação da Curva Característica}

Curva característica de um solo: A determinação da curva característica é fundamental para compreensão do comportamento de um solo não saturado. Essa curva representa uma função que correlaciona o volume de água dentro dos poros do solo com a energia necessária para a retirada dessa água. A Figura 4 apresenta uma curva característica típica para solos compactados, onde se pode identificar os pontos principais da curva característica (valor de entrada de ar e ponto de saturação residual) e os estágios identificáveis de dessaturação (zona limite de entrada de ar, zona de transição e zona residual de não saturação), conforme Vanapalli, Fredlund e Pufahl (1999).
O primeiro estágio identificável da curva característica é a zona limite de entrada de ar, que inicia com um valor de sucção próximo a zero e vai até a sucção correspondente ao valor de entrada de ar. Neste estágio quase todos os poros do solo encontram-se preenchidos por água. A sucção correspondente à entrada de ar identifica o ponto em que o ar começa a entrar no maior poro do solo não saturado. O próximo estágio da curva característica é a zona de transição, a qual inicia na sucção correspondente ao valor de entrada de ar e termina na correspondente ao ponto de saturação residual. $\mathrm{O}$ solo começa a dessaturar-se no estágio de transição e o teor de umidade reduz significativamente com o aumento da sucção. O ponto de saturação residual pode ser considerado como o teor de umidade além do qual torna-se difícil remover água do solo por drenagem, ou seja, a fase líquida encontra-se descontínua. O último estágio da curva característica é o estágio residual de não saturação e vai até a máxima sucção, ou seja, aquela correspondente ao teor de umidade próximo de zero.

Técnica do papel filtro: A técnica do papel filtro para medidas de sucção em solos não saturados foi criada pela Ciência dos Solos e pela Agronomia. O primeiro trabalho utilizando o método foi em 1937 desenvolvido por Gardner (FREDLUND; RAHARDJO, 1993) , mas foi a partir do final da década de 70 que tentativas da sua utilização para fins geotécnicos foram apresentadas (HO, 1979, KHAN, 1981; CHANDLER; GUTIERREZ, 1986). Mais recentemente, o ensaio foi padronizado pela Norma ASTM D 5298-92.

Quando um solo com uma determinada umidade é colocado em contato com um material poroso com capacidade de absorver água, os dois corpos terão uma troca de água até atingirem um equilíbrio. É nesta hipótese que o método do papel filtro se baseia. O papel filtro atingirá o equilíbrio de sucção (com relação ao fluxo de água) com uma amostra de solo na qual encontra-se em contato. A partir da umidade final do papel filtro e de uma calibração adequada é possível determinar indiretamente o valor da sucção existente no solo.

Procedimento do ensaio: Na realização deste ensaio foi adotado o procedimento padrão descrito na norma ASTM D 5298-03, com algumas alterações feitas a partir de observações e metodologias de outros pesquisadores como Rios Filho (2006) e Marinho (2000).

Uma das alterações no procedimento refere-se à sugestão da norma de que o papel filtro seja seco em estufa no mínimo por 16 horas antes da sua utilização no ensaio. $\mathrm{O}$ ensaio foi feito sem a secagem prévia, pois Marinho (2000) afirma que o procedimento de secar o 


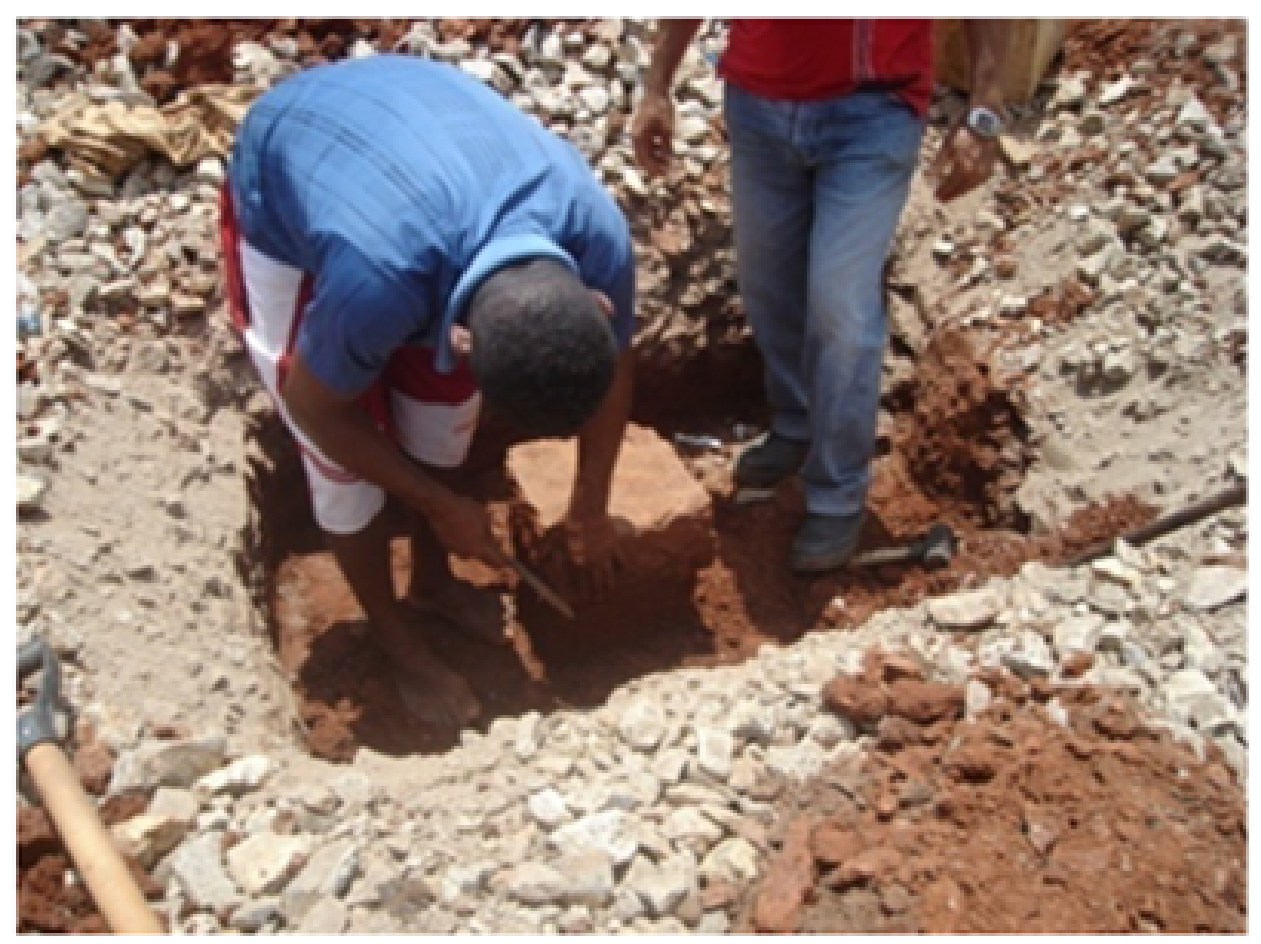

Figura 3: Extração dos blocos indeformados.

Tabela 1: Resultados dos ensaios geotécnicos.

\begin{tabular}{|c|c|c|c|c|c|c|c|c|c|c|c|}
\hline \multirow[t]{2}{*}{ Amostras } & \multicolumn{4}{|c|}{$\begin{array}{c}\text { Granulometria } \\
(\%)\end{array}$} & \multicolumn{3}{|c|}{$\begin{array}{c}\text { Limites } \\
\text { de } \\
\text { Attenberg } \\
(\%) \\
\end{array}$} & \multirow[t]{2}{*}{$\begin{array}{l}\text { Densidade } \\
\text { real }\end{array}$} & \multicolumn{2}{|c|}{ Compactação } & \multirow[t]{2}{*}{$\begin{array}{l}\text { Permeabilidade } \\
\qquad(\mathbf{m} / \mathbf{s})\end{array}$} \\
\hline & Pedreg. & Areia & Silte & Argila & $\mathbf{L L}$ & $\mathbf{L P}$ & IP & & $\begin{array}{c}\text { Umidade } \\
\text { ótima } \\
(\%)\end{array}$ & $\begin{array}{c}\gamma \\
\text { Seco } \\
\text { máximo } \\
\left(K N / m^{3}\right)\end{array}$ & \\
\hline 1 & 0 & 37 & 26 & 37 & 34 & 25 & 9 & 2,77 & 15,80 & 18,00 & $2,9 \times 10^{-9}$ \\
\hline 2 & 0 & 51 & 16 & 33 & 37 & 25 & 12 & 2,74 & 16,00 & 17,95 & $3,1 \times 10^{-9}$ \\
\hline
\end{tabular}




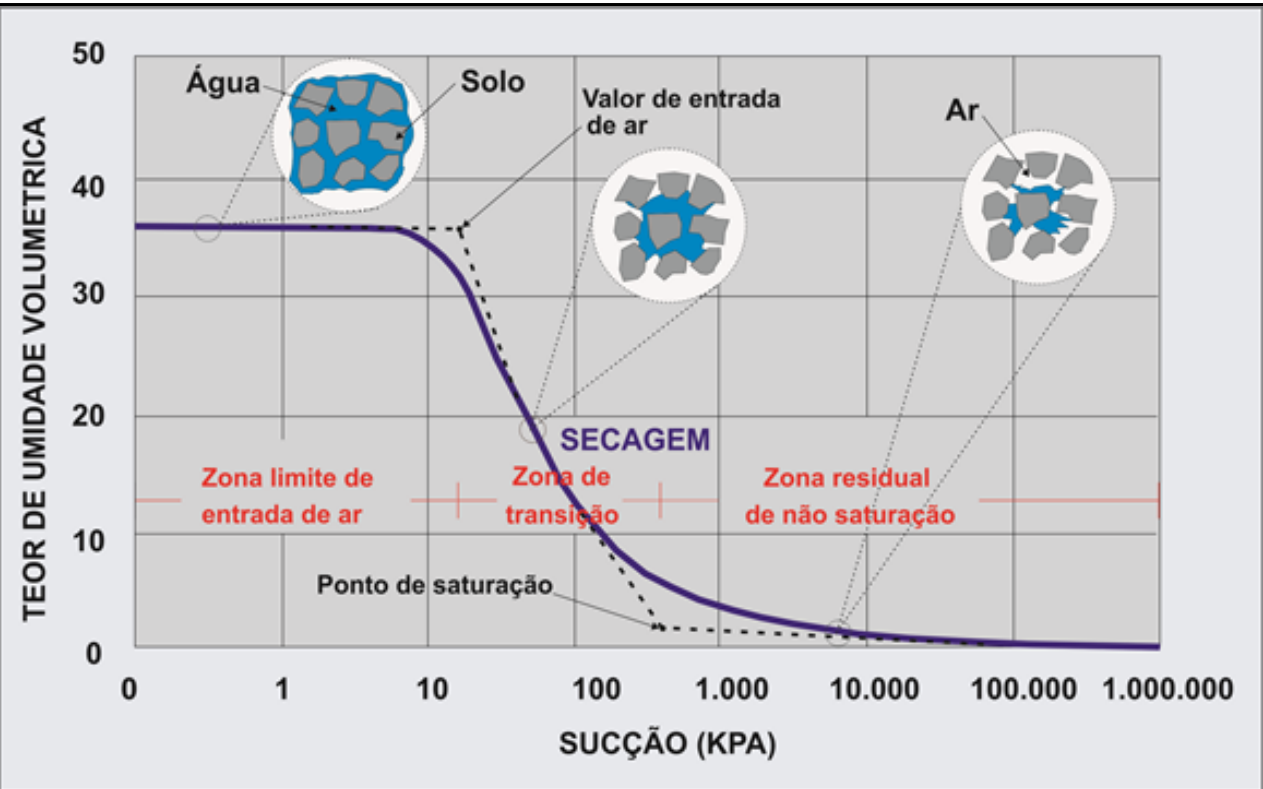

Figura 4: Curva característica.

papel filtro em estufa pode afetar as características de absorção do papel filtro.

Outra alteração se refere ao número de papéis filtro utilizados para uma mesma amostra e a forma de contato destes papéis com a amostra. Segundo a norma ASTM D 5298-03, para medir a sucção mátrica são colocados em contato com o solo três papéis-filtro entre duas amostras de solo. A sucção é medida em função do papel filtro do meio e os outros dois têm a finalidade de proteger o papel filtro central contra a aderência do solo no papel-filtro. No procedimento adotado nos ensaios realizados neste trabalho, foi utilizado apenas um papel filtro em contato com a amostra e um segundo papel filtro colocado sobre o primeiro papel. Neste caso, a sucção é medida a partir da umidade do segundo papel filtro, e o papel em contato com a amostra protege o segundo papel da aderência de grãos de solo que poderia alterar os resultados dos ensaios. Na Figura 5 a seguir é mostrado um comparativo deste procedimento.

O papel filtro usado nos ensaios foi o Whatman $\mathrm{N}^{\circ}$ 42 , no estado seco ao ar. O solo utilizado foi obtido da jazida de empréstimo da Barragem Pesqueiro. Inicialmente, as amostras foram compactadas na umidade ótima, e em seguida, foram obtidos corpos de prova pela cravação de anéis cilíndricos de aço inox, com $50 \mathrm{~mm}$ de diâmetro por $20 \mathrm{~mm}$ de altura. Cada anel foi colocado sobre a amostra compactada, e com auxílio de uma espátula, começou-se a "rasar" o solo envolta do anel. Este cuidado foi necessário para evitar forçar a penetração do anel no solo para que a amostra a ser ensaiada não seja amolgada, evitando alterar a estrutura do solo para que não influencie nos resultados finais.

Os corpos de prova foram colocados para secar ao ar por um período de tempo aleatório (variando desde $0 \mathrm{~h}$ até $72 \mathrm{~h}$ para cada conjunto de três amostras). Em seguida foram colocados sobre cada corpo de prova dois papéis filtro de formato circular com diâmetro de 50 $\mathrm{mm}$. O primeiro papel foi colocado em contato direto com a amostra, em seguida foi colocado o segundo papel sobre o primeiro. O primeiro papel tem o objetivo de evitar a aderência do solo em relação ao segundo papel que servirá para medir a sucção mátrica presente na amostra. Na Figura 6 são mostrados detalhes do procedimento.

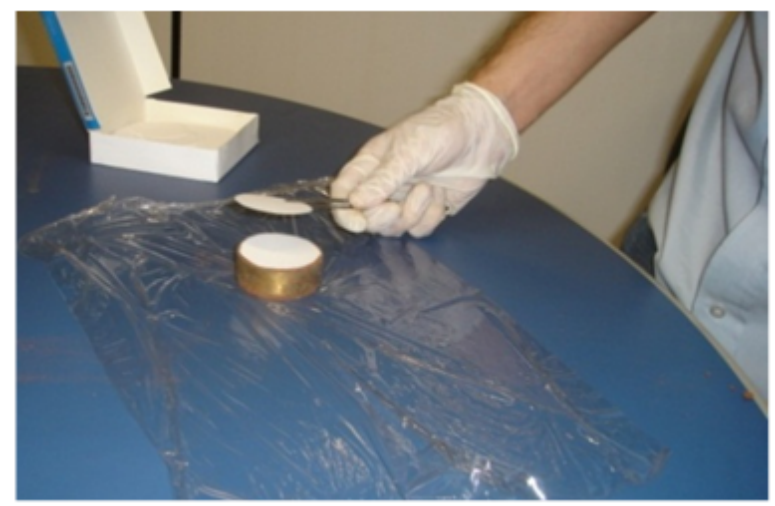

Figura 6: Colocação dos papéis filtro.

Conex. Ci. e Tecnol. Fortaleza/CE, v. 10, n. 2, p. 73 - 85, jul. 2016 

TERRA

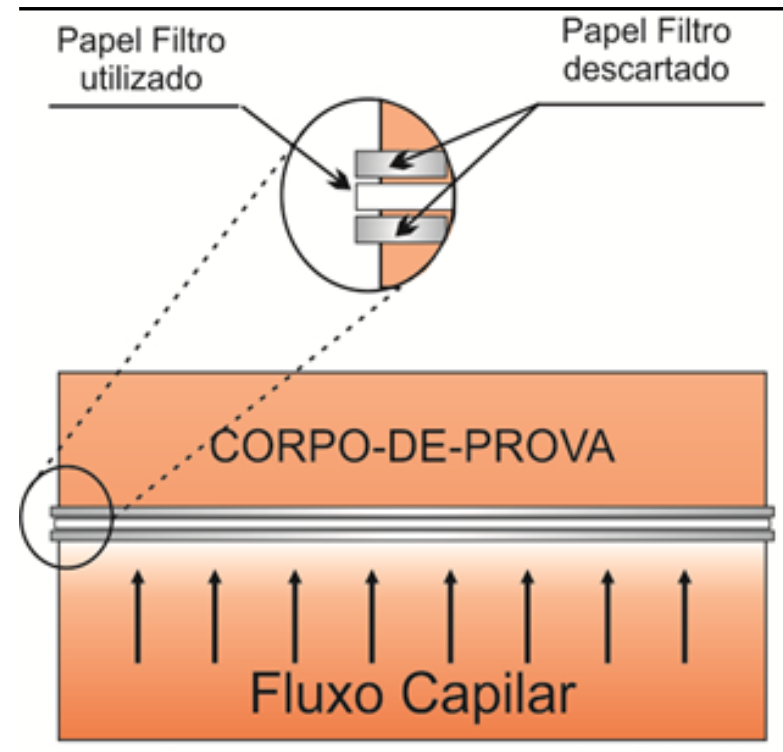

Procedimento pela Norma ASTM D 5298-03

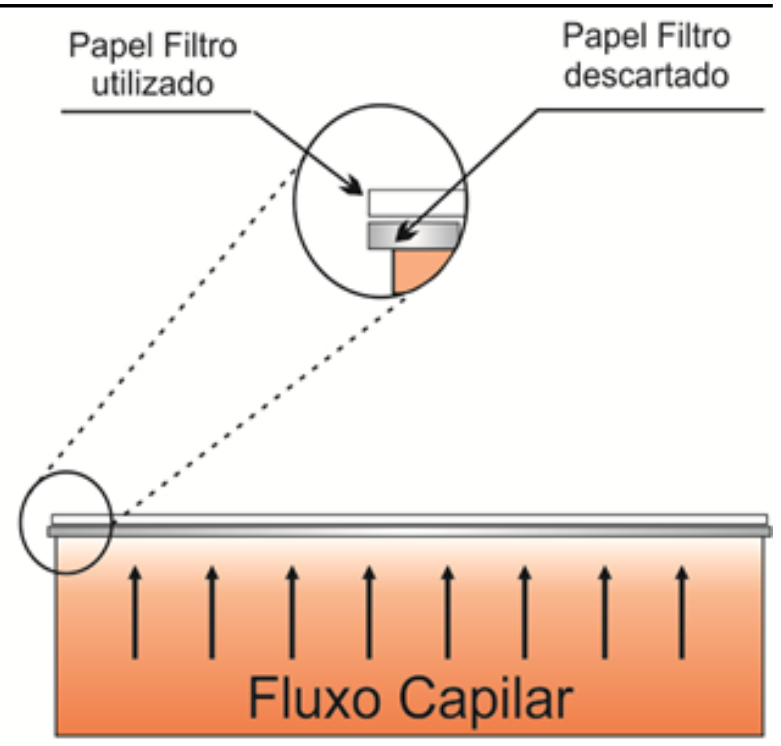

Procedimento adotado

Figura 5: Comparativo do procedimento adotado e sugerido pela Norma ASTM D 5298-03.

A amostra e os papéis filtro foram envolvidos com filme de PVC para evitar a perda de umidade, e em seguida, envolvidas com papel alumínio, aumentando o isolamento do conjunto. Após o envolvimento, as amostras foram colocadas dentro de uma caixa de isopor para garantir que as amostras não sofressem grandes variações térmicas durante o período de equalização da sucção entre o papel filtro e a amostra.

O período de equalização adotado entre o papel filtro e as amostras foi de sete dias. Este período foi determinado segundo recomendações da Norma ASTM D 5298-03, no qual cita que o tempo mínimo de equalização entre o solo e o papel filtro é de sete dias, e que após este prazo se determina a umidade do papel filtro.

Resultados do experimento: Após o período de equalização, as amostras foram desembrulhadas e o papel filtro foi retirado, com menor tempo possível, com o auxílio de uma pinça metálica e colocado dentro de uma cápsula metálica com tampa. A cápsula com os papéis filtro foi pesada em uma balança com precisão de $( \pm 0,0001 \mathrm{~g})$ e levada para a estufa com temperatura de $70{ }^{\circ} \mathrm{C}$. É importante destacar que toda operação de retirar o papel filtro da amostra e colocar na cápsula foi executado de forma que o papel não ficasse exposto ao ar por mais de 5 (cinco) segundos, tendo o objetivo de evitar a perda ou ganho de umidade. Após a pesagem, os papéis filtro foram colocados na estufa por um período mínimo de 24 horas. Depois de decorrido este tempo os papéis filtro secos foram pesados novamente, obtendo-se assim o teor de umidade após equalização com a sucção da amostra de solo.

Após a obtenção de umidade do papel filtro, os valores de sucção para cada valor de umidade foram determinados por meio das seguintes equações do papel filtro Whatman $\mathrm{N}^{\mathrm{o}} 42$ obtidas por Chandler, Crilly e Smith (1992), que definem as relações entre umidade e sucção.

Para a umidade do papel filtro "w" > 47\%:

$$
S_{m}(k P a)=10^{(6,05-2,48 \log w)}
$$

Para a umidade do papel filtro "w" $\leq 47 \%$ :

$$
S_{m}(k P a)=10^{(4,84-0,0622 \log w)}
$$

Com base nos valores obtidos dos ensaios, traçouse uma curva que interpola os pontos obtidos. Para esta curva ajustada, foi utilizada nessa pesquisa a equação proposta por Fredlund e Xing (1994). A equação proposta é a apresentada a seguir:

$$
\Theta(k P a)=C_{\psi} \frac{\Theta_{s}}{\left\{\ln \left[e+\frac{\Psi}{a}^{n}\right]\right\}^{m}}
$$

Onde temos: $\Phi$ - sucção; $s$ - Umidade Volumétrica na saturação; $a, n$, e $m$ - Parâmetros de ajuste da curva.

Por meio de uma planilha eletrônica, a curva característica foi traçada, partindo de um campo de sucção variando de 0 a $10.000 k P a$, para uma porosidade de 0,33 e com base nos parametros a, $\mathrm{n}$ e m (definidos de forma aleatória), obteve-se uma curva bem ajustada 


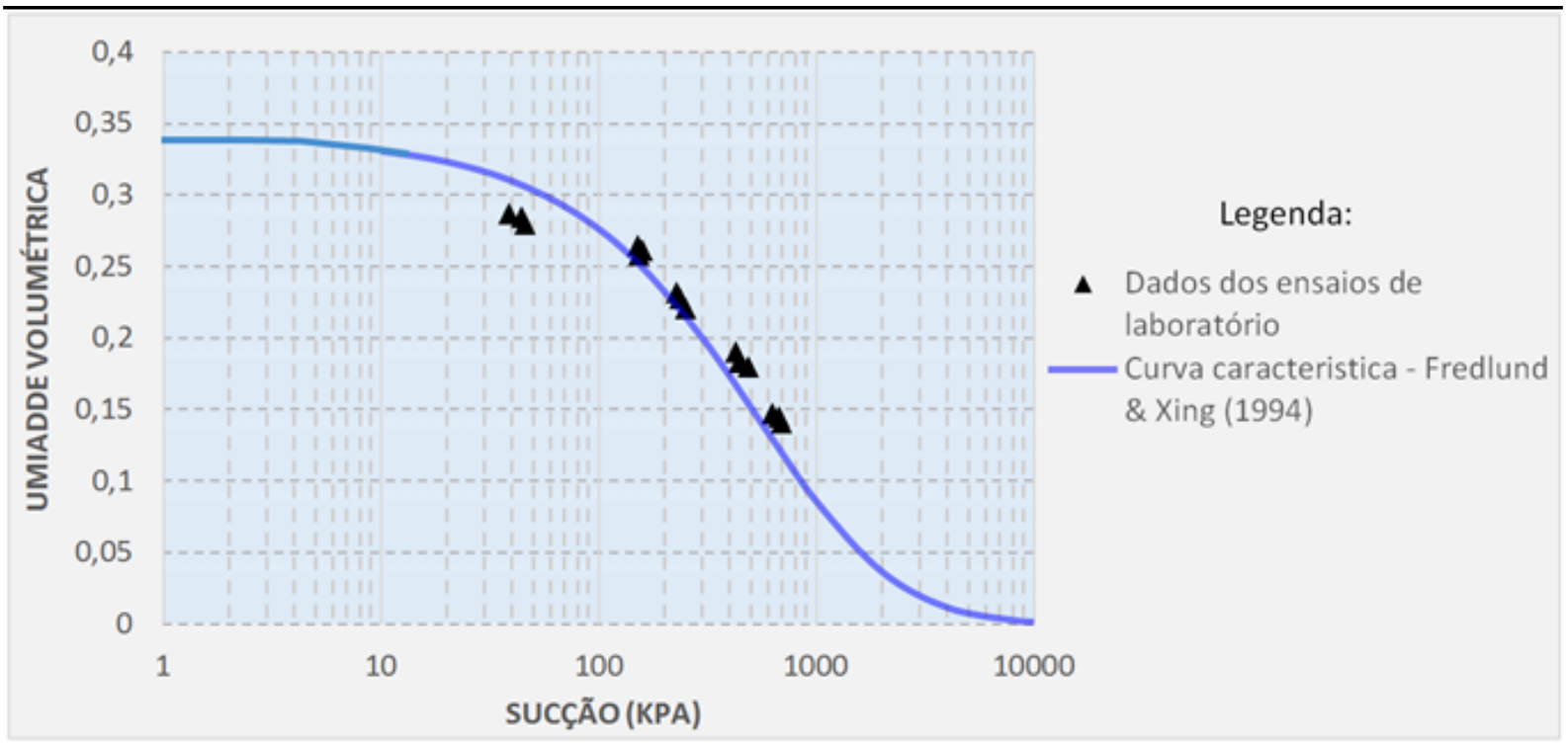

Figura 7: Gráfico da curva característica.

aos pontos dos ensaios, conforme podemos visualizar no gráfico da Figura 7

\subsubsection{Ensaios de Cisalhamento Direto}

Generalidades: Para se obter os parâmetros de resistência para os solos estudados, nas condições saturada e não saturada, optou-se por utilizar o ensaio de cisalhamento direto. Apesar deste ensaio possuir algumas desvantagens como: a imposição de um plano de cisalhamento horizontal, a incerteza da saturação da amostra, dentre outros, não deixa de ser um ensaio bastante versátil e útil quanto à obtenção apenas dos parâmetros de resistência ao cisalhamento.

Os ensaios de cisalhamento direto foram feitos com corpos de prova retirados dos Blocos 01 e 02 de "amostras indeformadas" provenientes do maciço da Barragem Pesqueiro. As tensões adotadas foram definidas de acordo com o estado de tensões atuantes na barragem, de forma que as amostras foram ensaiadas com tensões normais de 50, 100 e $200 \mathrm{kPa}$.

Resultados dos ensaios de cisalhamento direto: Os ensaios de cisalhamento saturado foram realizados em três amostras que foram extraídas do Bloco 01. É importante ressaltar com relação à saturação da amostra, que o corpo de prova foi ensaiado numa condição inundada, com um período mínimo de saturação de 24 horas. Com relação aos resultados do ensaio no estado saturado, foi obtido um ângulo de atrito no valor de $31,9^{\circ}$ e uma coesão no valor de $13,2 \mathrm{kPa}$.
Para os ensaios de cisalhamento direto não saturado, as amostras foram ensaiadas sem inundação. Foram realizados dois conjuntos de ensaios, sendo um conjunto realizado no Bloco 01 que possuía um baixo teor de umidade (cerca de 9,4\%) e o segundo conjunto de ensaios foi realizado no Bloco 02 de umidade um pouco maior (cerca de 10,2\%).

Pelos resultados obtidos, pode-se verificar que os parâmetros de resistência obtidos para as amostras em seu estado não saturado foram bem elevados em relação ao seu estado saturado. Pelas envoltórias de ruptura, foi verificado que o Bloco 01 teve uma coesão de 130,5 $k P a$ com um ângulo de atrito de $35,8^{\circ}$. Para o Bloco 02 , obteve-se um valor de coesão de $120,5 \mathrm{kPa}$ e um ângulo de atrito de $33,5^{\circ}$. É importante ressaltar que a elevada coesão observada nos ensaios não saturados é chamada de coesão aparente, pois é atribuída ao baixo grau de saturação do corpo de prova e o alto valor de sucção atuante na amostra.

Determinação do parâmetro $\phi^{b}$ : A sucção ou pressão negativa de água provocam aumento de resistência do solo. Este acréscimo de resistência pode ser estimado pela seguinte equação proposta por Fredlund, Morgenstern e Widger (1978) mostrada abaixo.

$$
\tau_{r}=c^{\prime}+\left(\sigma-u_{a}\right)_{r} \tan \phi^{\prime}+\left(u_{a}-u_{w}\right)_{r} \tan \phi^{b}
$$

Em que $u_{a}=$ Pressão do ar $u_{w}=$ Pressão da água $\phi^{b}$ = parâmetro que quantifica o acréscimo de resistência relativo ao aumento de sucção. 


\begin{abstract}
Através dos resultados obtidos nos ensaios de cisalhamento direto, e com base no teor de umidade das amostras ensaiadas e da curva característica obtida com o método do papel filtro, fez-se uma estimativa dos valores de sucção para cada amostra. Para uma umidade média de $10 \%$ obteve-se um valor de sucção médio de $500 k P a$ de sucção. A partir dos valores de sucção atuantes nos blocos ensaiados, com base nos valores de resistência do solo saturado e tensões de cisalhamento, determinou-se o valor médio de $b^{\mathrm{o}}$.

Deve-se destacar que a estimativa da sucção dos corpos de prova com base no teor de umidade tem suas limitações, pois existe variação de umidade dos corpos de prova no decorrer do ensaio, que consequentemente altera a sucção atuante. Contudo, para fins práticos, esta é uma alternativa razoável de se determinar a sucção nas amostras de solo.
\end{abstract}

\section{SIMULAÇÃO DAS CONDIÇÕES DE FLUXO ESTACIONÁRIO E TRANSIENTE}

\subsection{Generalidades}

As análises de fluxo têm por objetivo investigar as condições de percolação em função das propriedades do solo e das condições de carregamento durante o período de enchimento e operação da barragem. Para estas análises utilizou-se o software SEEP/W (GEO-SLOPE) 2007) em que adota o Método de Elementos Finitos para as soluções de fluxo em meio poroso.

A geometria tomada como base nas análises corresponde à seção máxima da Barragem Pesqueiro, mostrada na Figura 8. Para os dados de entrada, foram considerados os materiais referentes ao solo compactado, dreno de areia, dreno de pé e rip-rap. Para a simplificação do problema, assumiu-se que todos os materiais presentes na seção são homogêneos.

As condições de contorno adotadas nas análises de fluxo transiente foram referentes às variações de carga hidráulica no reservatório que ocorrem durante o enchimento do reservatório, e condições de precipitações e evaporações durante os períodos de inverno e estiagem. O regime de enchimento e operação do açude Pesqueiro foi simulado com bases em informações obtidas junto a Companhia de Gestão dos Recursos hídricos do estado do Ceará - COGERH, referente aos primeiros seis anos de operação (Janeiro/2008 a Dezembro/2013).

Durante a operação, o açude passou por dois períodos de enchimento, sendo o primeiro no inverno do ano de 2008 e o último no inverno do ano de 2009, momento em que o reservatório sangrou pela primeira vez com uma lâmina máxima de 1,19 m. Desde deste ano, o açude Pesqueiro tem passado por um esvaziamento do reservatório, ocasionado pelos longos períodos de seca ocorridos nos últimos anos. A Figura 9 apresenta a variação do nível d'água do reservatório nos últimos anos.

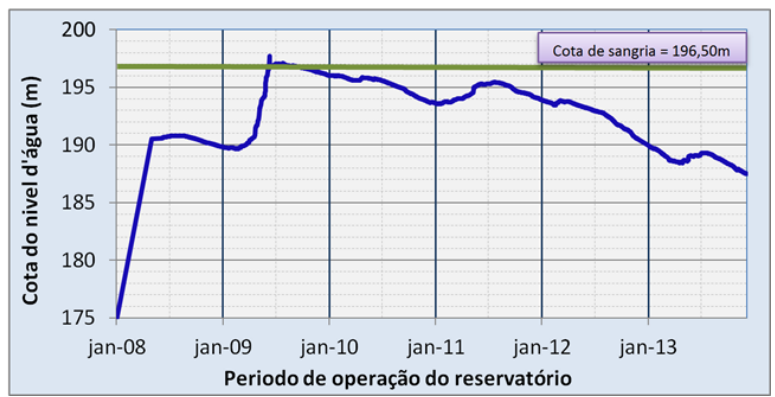

Figura 9: Enchimento da

Barragem Pesqueiro com 1440 dias de enchimento - Jan/2010 a Jan/2012.

Além dos dados de variação do nível d'água, também foram obtidos junto a COGERH dados de variação de carga hidráulica de piezômetros que estão instalados no maciço. Com essas informações, foi possível calibrar o modelo de forma a obter respostas semelhantes de variação de poro-pressão em relação à variação do nível d'água do reservatório.

\subsection{Simulações transientes durante a operação do reservatório}

As simulações transientes bi-dimensionais foram realizadas para um período de tempo de 2160 dias (aproximadamente seis anos) de operação da Barragem Pesqueiro. A seguir nas Figuras 10, 11] e 12 são apresentados resumos dos resultados das análises de fluxo transientes para cada período de dois anos analisado, mostrando o comportamento da linha freática a cada 90 dias.

Pelas simulações realizadas, é possível observar o avanço da linha freática e da região de saturação. Os resultados mostram certo atraso do avanço da linha freática em relação ao nível do açude, principalmente nos primeiros dois anos de enchimento, sendo isto explicado devido a decorrência da baixa permeabilidade do maciço. É importante destacar que o avanço da linha freática influenciará na estabilidade da barragem, no qual será mostrado nos estudos de estabilidades de taludes.

Os resultados mostram que durante o período de enchimento da barragem Pesqueiro, o fluxo pelo maciço tende a se estabilizar com quatro anos (1440 dias). Contudo, à medida que o nível d'água baixa no reservatório, influenciado pelo grande período de estiagem que 

TERRA

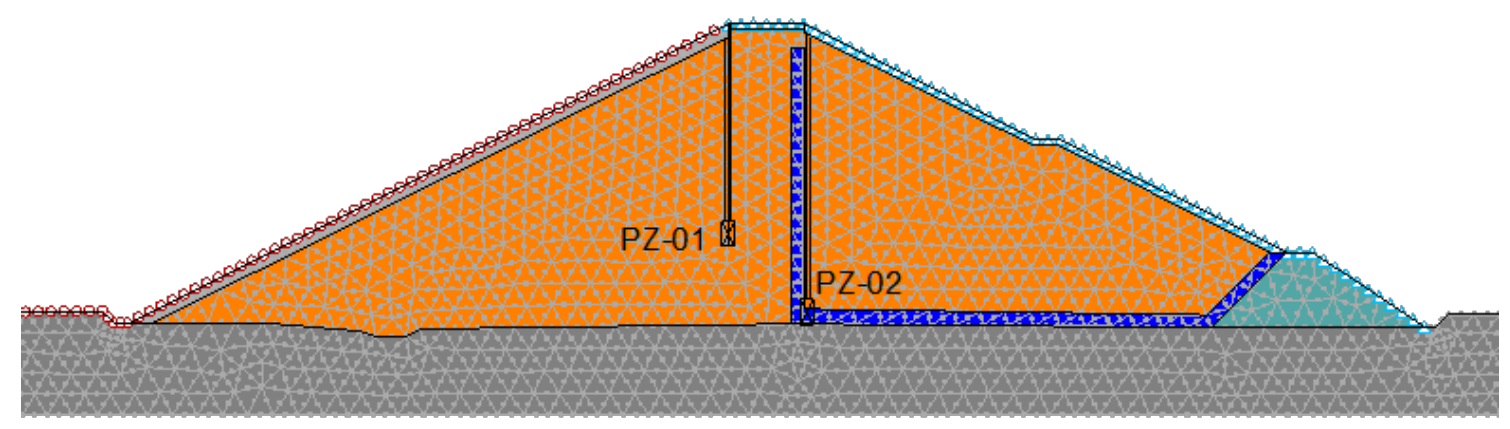

Figura 8: Malha de Elementos Finitos.

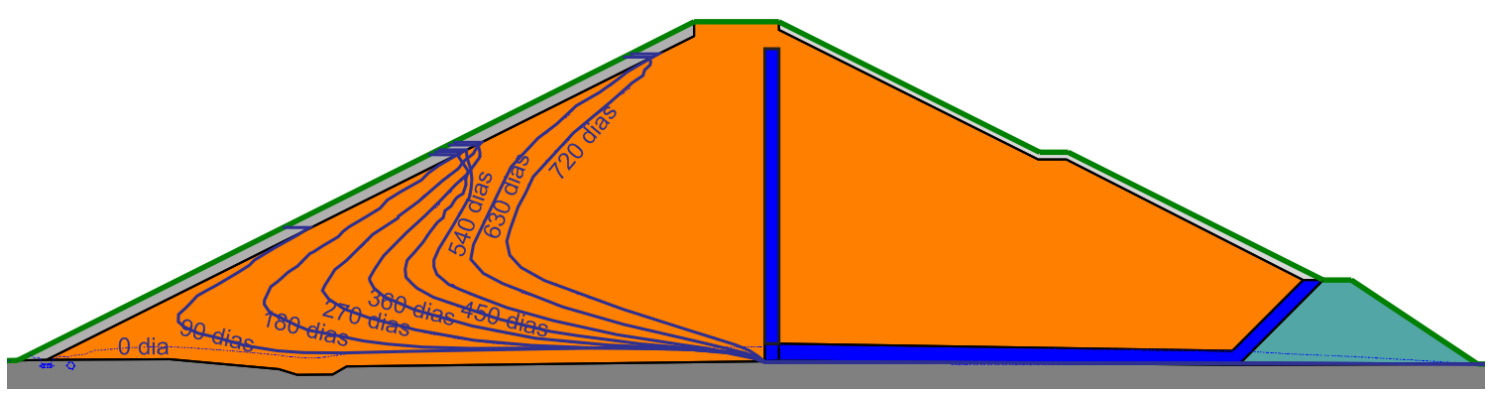

Figura 10: Análise de fluxo da Barragem Pesqueiro com 720 dias de enchimento - Jan/2008 a $\mathrm{Jan} / 2010$.

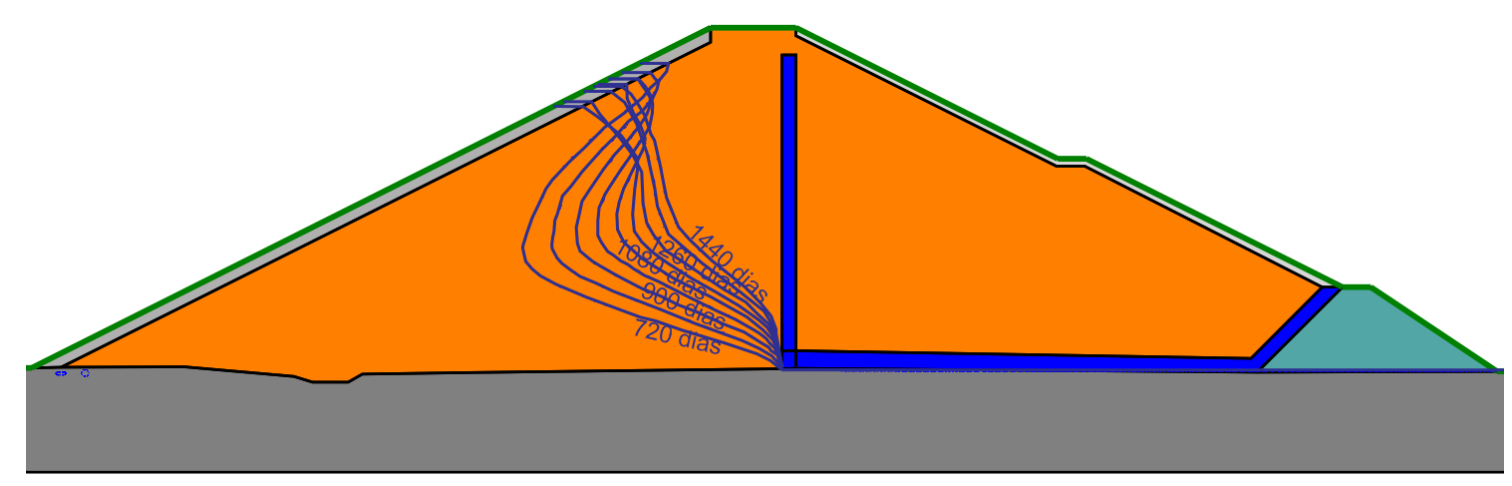

Figura 11: Análise de fluxo da Barragem Pesqueiro com 1440 dias de enchimento - Jan/2010 a

$$
\text { Jan/2012. }
$$

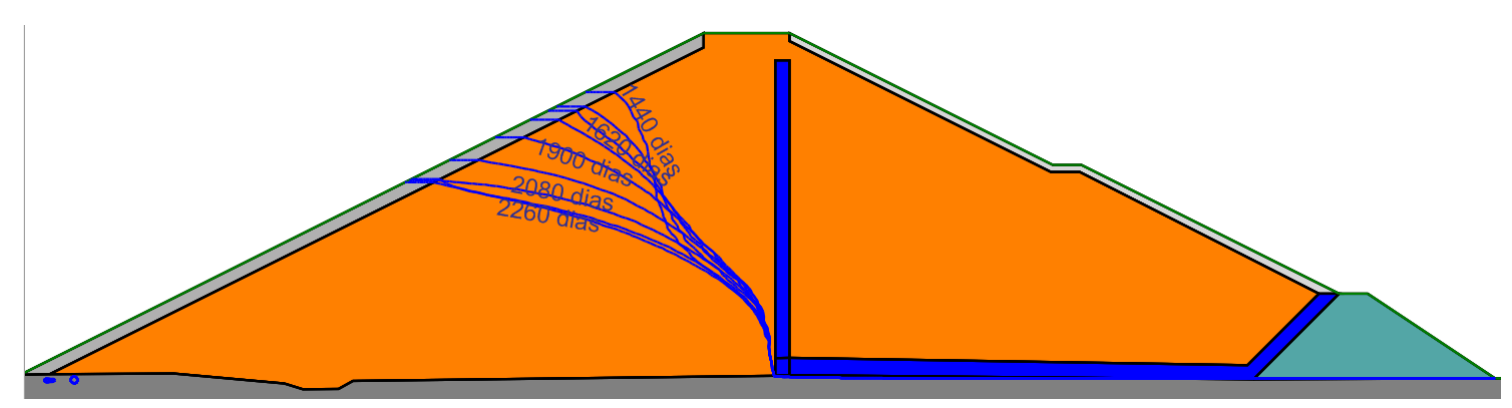

Figura 12: Análise de fluxo da Barragem Pesqueiro com 2260 dias de enchimento - Jan/2012 a $\mathrm{Jan} / 2014$. 
existe neste período estudado, faz com que o ocorra reduções significativas de poro-pressão interna de forma que a linha freática tende a rebaixar para montante.

\section{ANÁLISES DE ESTABILIDADE DE TALU- DES}

\subsection{Descrição das análises}

Foram analisadas as estabilidades dos taludes de montante e jusante da Barragem Pesqueiro, levando em consideração a variação de poro-pressão e sucção no maciço. Os cálculos foram realizados com base nas análises de fluxo, obtendo-se Fatores de Segurança para ambos os taludes, a cada período de tempo de 90 dias e ao longo dos seis anos de operação (período de 2260 dias).

Com o objetivo de avaliar a influência da sucção atuante a estabilidade da barragem, as análises de estabilidade foram realizadas por duas metodologias: considerando a influência de apenas a poro-pressão da água (metodologia de análise de estabilidade tradicional) e, considerando a influência da sucção no aumento de resistência do maciço (utilizando os princípios da Mecânica dos Solos Não Saturados). Para estas análises, utilizou-se o programa computacional SLOPE/W (GEO-SLOPE, 2007), no qual adota o método de estabilidade "Morgenstern-Price".

Os parâmetros pertinentes ao estudo de estabilidade são basicamente o peso específico do material e os parâmetros de resistência (coesão, e b). Os parâmetros para o solo compactado foram determinados com base nos resultados de laboratório. Os parâmetros para os demais materiais como filtro, rip-rap e rockfill foram estimados segundo a literatura disponível.

Um resumo dos parâmetros geotécnicos adotados é apresentado na Tabela 2 .

\subsection{Resultados das análises de estabilidade du- rante a operação do reservatório}

Os resultados de estabilidade são apresentados em gráficos, comparando para cada talude, a variação dos Fatores de Segurança ao longo do tempo para cada metodologia (tradicional e adotando os parâmetros de solos não saturados).

A estabilidade do talude de jusante apresentado no gráfico da Figura 13, pode-se verificar que não houve grandes variações no valor do Fator de Segurança, tanto pela metodologia tradicional quanto pela metodologia em que considera a influência da sucção no maciço. Isto se deve ao sistema de drenagem interna localizado na parte central da barragem, que faz com que o talude de jusante não tenha grandes variações de poro-pressão e de sucção.
Outro fato que se deve destacar é com relação à diferença entre as duas metodologias, pois quando não se considera a influência da sucção no maciço, o Fator de Segurança para o talude de jusante apresenta o valor de aproximadamente $\mathrm{FS}=1,81$ enquanto que para a metodologia que considera a influência da sucção no cálculo da estabilidade o Fator de Segurança é de 2,10, uma diferença de 13,8\% entre os Fatores de Segurança.

Para o talude de montante, conforme pode ser visto na Figura 14, existe uma grande diferença da variação do Fator de Segurança (pico máximo de 29,6\% de diferença entre os Fatores de Segurança), principalmente no primeiro ano de enchimento. Isto ocorre pois grande parte do talude de montante ainda não está saturado e desta forma, existe aumento de resistência por causa da sucção atuante. Pela mecânica dos solos tradicional, o Fator de Segurança calculado é bem menor, pois não leva em conta o ganho de resistência gerada pela sucção.

Verificamos ainda que conforme ocorre o esvaziamento do reservatório ao longo dos anos, a estabilidade do talude reduz. Isto é devido a minimização dos esforços do empuxo da água sobre o talude de montante em função da redução do nível do açude. A diferença entre os Fatores de Segurança calculados por ambas a metodologias também não é relevante durante o período de esvaziamento (diferença média em torno de 5\%).

\section{CONSIDERAÇÕES FINAIS}

O método do papel filtro apresentou resultados satisfatórios para a determinação da relação entre o teor de umidade e a sucção presentes nos solos parcialmente saturados, mostrando ser uma alternativa simples e vantajosa.

Com relação às simulações de fluxo realizadas durante o período de operação da Barragem Pesqueiro, foi possível determinar o avanço da região de saturação, bem como o desenvolvimento das poro-pressões ao longo do período simulado.

As análises de estabilidade referentes ao período de operação mostraram que para o talude de jusante não ocorrem grandes variações de estabilidade devido ao sistema de drenagem interna, contudo é apresentada uma diferença média de 13,8\% entre os Fatores de Segurança quando comparado com a metodologia tradicional e considerando a presença da sucção.

Para o talude de montante, verificamos alterações significativas na estabilidade do maciço ao longo do período estudado. Durante o enchimento do reservatório, ocorre aumento de estabilidade devido ao empuxo da água no talude. Já no período de esvaziamento, é observado redução dos Fatores de Segurança. Quanto a 
Tabela 2: Parâmetros geotécnicos adotados nas análises de estabilidade de taludes.

\begin{tabular}{ccccc}
\hline Material & Peso específico $(K n)$ & Coesão $(k P a)$ & Ângulo de Atrito $\left(^{\circ}\right)$ & $\phi^{b}\left({ }^{\circ}\right)$ \\
\hline Solo Compactado & 18,50 & 13,20 & 31,90 & 17,00 \\
Filtro de areia & 19,00 & 0,00 & 30,00 & - \\
Enrocamento & 21,00 & 0,00 & 42,00 & - \\
\hline
\end{tabular}

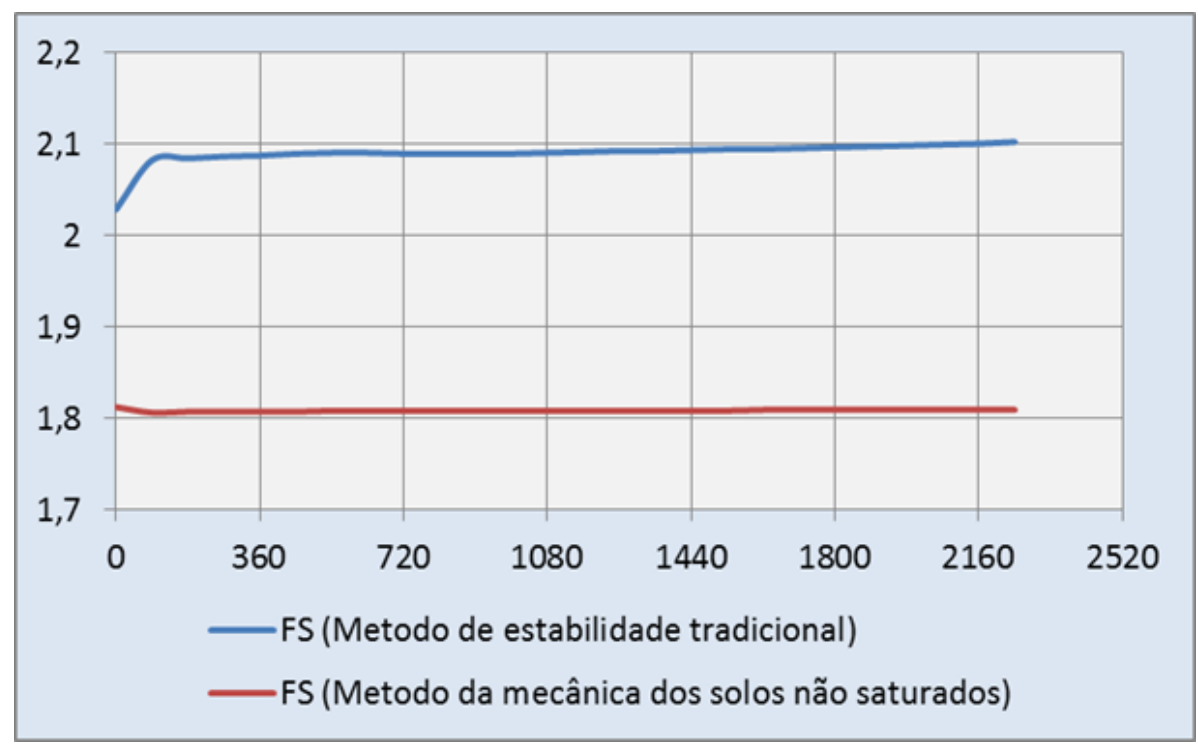

Figura 13: Variação do Fator de Segurança no talude de jusante, para um período de 2260 dias.

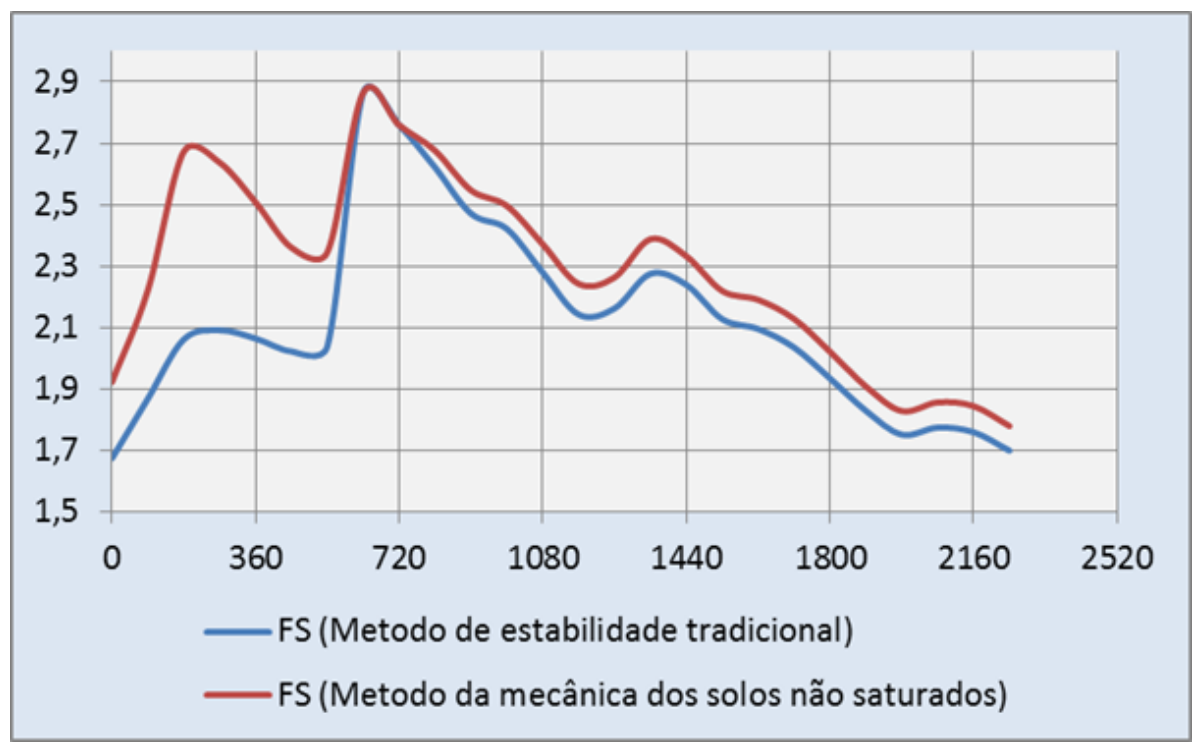

Figura 14: Variação do Fator de Segurança no talude de montante, para um período de 2260 dias. 
influência da sucção no Fator de Segurança, as maiores diferenças entre as metodologias é apresentado durante o período de enchimento (valor máximo de $29,6 \%$ de diferença). No período de esvaziamento, as diferença de resultado são em média da ordem de $5 \%$.

Também foi possível constatar a importância do emprego dos conceitos da mecânica dos solos não saturados nos estudos de estabilidade de taludes de barragens de terra, pois os resultados mais precisos e menos conservadores da metodologia podem servir de base para definir projetos mais econômicos.

\section{REFERÊNCIAS}

CHANDLER, R.; CRILLY, M.; SMITH, M. A low-cost method of assessing clay desiccation for low-rise buildings. In: THOMAS TELFORD-ICE VIRTUAL LIBRARY. Proceedings of the Institution of Civil Engineers-Civil Engineering. [S.1.], 1992. v. 92, n. 2 , p. 82-89.

CHANDLER, R.; GUTIERREZ, C. The filter-paper method of suction measurement. Géotechnique, Thomas Telford Ltd, v. 36, n. 2, p. 265-268, 1986.

FREDLUND, D.; MORGENSTERN, N. R.; WIDGER, R. The shear strength of unsaturated soils. Canadian geotechnical journal, NRC Research Press, v. 15, n. 3, p. 313-321, 1978.

FREDLUND, D. G. Soil mechanics for unsaturated soils. Sask: University of Saskatchewan, 1993.

FREDLUND, D. G.; RAHARDJO, H. Soil mechanics for unsaturated soils. New York: John Wiley \& Sons, 1993.

FREDLUND, D. G.; XING, A. Equations for the soil-water characteristic curve. Canadian geotechnical journal, NRC Research Press, v. 31, n. 4, p. 521-532, 1994.

GEO-SLOPE. GeoStudio 2007. [S.1.]: GEO-SLOPE International Ltd Calgary, AB, 2007.

HO, D. Y. F. Measurement of Soil Suction Using the Filter Paper Technique, Internal Report, IR-11, Transportation and Geotech. Canada, 1979.

IPECE. Instituto de Pesquisa e Estrategia Economica do Ceara. Base Cartografica Digital do Estado do Ceara. Abril 2012. Acesso em: 03 abr. 2012.

KHAN, A. H. Evaluation of Laboratory Suction Tests by Filter Paper Technique for Prediction of Heave in Expansive Soils, Report n. GM-81-001. [S.1.], 1981.
MARINHO, F. A. M. Soil Suction Measurement in Soils and Porous Materials. Denver, Colorado, 2000.

OLIVEIRA, O. M. de. Estudo sobre a resistência ao cisalhamento de um solo residual compactado não saturado. Tese (Doutorado) — Universidade de São Paulo, 2004. 330 p.

RIOS FILHO, M. G. Comportamento de um Aterro Compactado em Campo e Laboratório. Dissertação (Mestrado em Ciências em Engenharia Civil) Universidade Federal do Rio de Janeiro - UFRJ, Rio de Janeiro, 2006.

VANAPALLI, S.; FREDLUND, D.; PUFAHL, D. The influence of soil structure and stress history on the soil-water characteristics of a compacted till. Géotechnique, Thomas Telford Ltd, v. 49, n. 2, p. 143-159, 1999. 